\title{
Rurality in Colombia: We Still Have a Lot to Change/ Too Much to Do
}

\author{
Jesus David Ponce Mendoza* \\ Department of Agroforestry, Technological University of Chocó-UTCH, Colombia
}

Received: 眥July 12, 2018; Published: 䟧July 25, 2018

*Corresponding author: Jesus David Ponce Mendoza, Department of Agroforestry, Technological University of Chocó-UTCH, Colombia

\section{Mini Review}

"For a dignified rurality, Colombia not only needs a comprehensive and equitable rural reform, but also a political system free of impurities" (Ponce-Mendoza, 2018). We are facing a situation that had to be treated differently for a long time, since in fact it is different, and during the last 15 or 20 years nothing productive has been done about it. It is very clear that it is necessary to improve the living conditions of rural inhabitants, the municipal vulnerability and rurality indices show that it is a priority [1]. Therefore, it is vital to design and implement differential public policies that meet the needs of the rural population in each region of the country; we do not need the same policies as always: "that favor the few at the cost of sweat and the work of many, that is, that the poor work more and become poorer day by day, and that the rich work less and become richer every day, but at the expense of the work of the poor."

What is really required is that things be done with fairness and equity, not with them and for their benefits (marmalade), we need new ideals that go hand in hand with optimal socioeconomic development, which positively impacts human well-being. It is demonstrated in Colombia that the persistence of political elites negatively affects the welfare of the population [1], this can be expressed as a directly proportional relationship between political persistence and unmet basic needs (NBI), since, the municipalities with greater political persistence have higher NBI levels. But such is the degree of control of elections by elites that they are not considered to be free and clean, which has been evidenced, among other actions, in the intervention of armed groups outside the law, which its armed force distorts the results of the public elections, putting the balance to its own benefit and that of its political allies (Parapolitics, Farcpolitics, etc). Of this type of facts, the peasantry, rural women, indigenous peoples and Afro-Colombian communities have been the most affected. Facts to which the non-recognition as a social group is added, It is known that rural women are subjected to triple discrimination because they live in the countryside, because they are women and because they are victims of violence [1], most of whom are mothers who are heads of households, who live together free, in humble dwellings, which scarcely have permanent electric power service because in some cases they resort to alternative energy sources, since they do not have an aqueduct service, the water they consume is rain and, in some cases, streams or rivers.

This is supported by the fact that the municipalities with the highest concentration of Afro-Colombian and indigenous population are those with the highest incidence of NBI [1]. In addition, it is evident that more than half of the indigenous population lives below the poverty line and the rest of it is in the line of misery, with a considerable percentage of illiteracy. Regarding the existing institutionality, generally in urban centers and municipal capitals, the progress will be based on its scope, since, in the change of the institutional structure, fields of action such as planning, management and care were lost. natural resources [1]. Without these, the institutions do not impact enough to generate positive changes that prevent the difficult living conditions for the inhabitants of the countryside from continuing to present themselves and that also improve them substantially. Because, systematically, the state distorted the sense of rural development, intentionally weakening its actions in this crucial area, creating ineffective and inefficient UMATAS, EPSAGROS and SECRETARIATS, with almost no presence in rural communities and full of unskilled personnel. for such charges.

Because of the above and many other political decisions taken for the curse of many and the benefit of few, today the sector is facing very serious deficiencies in productive infrastructure, in research, technology transfer, optimal technical assistance and other useful mechanisms to provide support. what small and medium producers really need in rural development [1]. That is why it is necessary to implement policies that favor the poorest, policies that generate a progressive development of the rural class, which are formulated based on the recognition of the diversity of socio-economic, environmental, agro-ecological and cultural conditions present. 
in rural areas. That is why economic development must guarantee the protection of the environment, regulating to the maximum the rhythm of extraction of non-renewable natural resources in a way that diminishes the negative impact on water, soils and biodiversity, since these are fundamental for the development of rural activities [2]. In addition, it is very important in a certain way to put aside selfishness and start promoting and executing actions in order to guarantee the welfare not only of the current generation, but also of the future ones.

For scholars it is nota secret, that a true structural transformation of the field requires adopting measures to promote the proper use of the land in accordance with its vocation and encourage the formalization, restitution and equitable distribution of it, in search of well-being and good live. So, it is seen with good eyes that in the Final Agreement for Peace [3] the National Government plans to make available to the beneficiaries of the Land Fund, housing support plans, technical assistance, training, land adequacy, productive projects, among other mechanisms of support for the generation of income and the overcoming of poverty, strategies that hopefully not only remain on paper as is customary in this country. It is worth highlighting that it is vitally important to implement the Development Plans with Territorial Approach (PDET), Peasant Reserve Zones, and others that the Government defines [3]. But as long as the social function of rural property and, in particular, family farming is protected. It is that overcoming poverty is not achieved simply by improving the income of families but ensuring that they have adequate access to public services and goods. Because to have prosperity, it is necessary to take advantage of and exploit the available resources, inventing and innovating products, applying new technologies, so that there is a sustainable development and equality of conditions for all people, especially rural communities.

This will only be possible when we change the way we think and leave the conformism, when people choose political representatives who think about the welfare of all and that generate alternatives for progress aimed at total sustainability. Since not only a new era or generations are required to be directed to economic growth, but also to give the guarantee that each generation must have the natural resources necessary for its growth and survival, because to be at peace, we must all be on equal terms, which is far beyond what has been established in the Colombian Constitution.

\section{References}

1. UNDP (2011) Rural Colombia: Reasons for hope. Executive Summary. National Human Development Report 2011. United Nations Development Program-UNDP. Bogota, Colombia. pp. 70.

2. Ocampo J (2014) Mission for the transformation of the field: Settle the historical debt with the field. Conceptual framework of the Mission for the Transformation of the Field. Page 4-8. National Department of Planning. Bogota, Colombia

3. Final Agreement (2016) Final agreement for the termination of the conflict and the construction of a stable and lasting peace. Pag 1113. National Government and Revolutionary Armed Forces of ColombiaPeople's Army. Havana, Cuba.

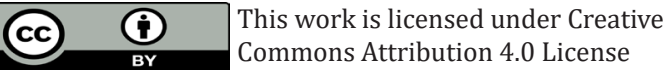

To Submit Your Article Click Here: Submit Article
DOI: 10.32474/CIACR.2018.03.000173

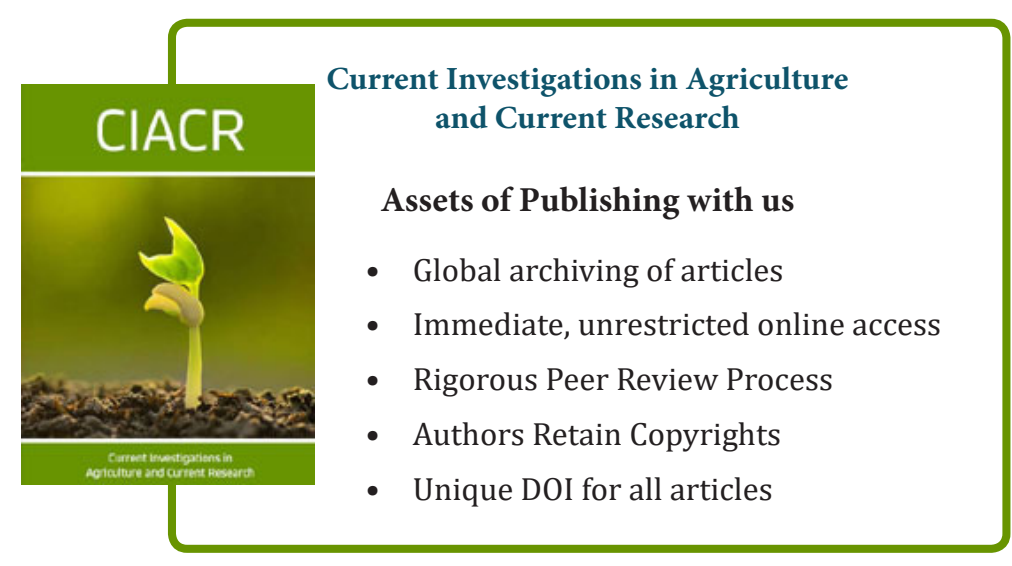

